\title{
Dementia and cognitive impairment in Parkinson's disease
}

\author{
F GIROTTI, P SOLIVERI，F CARELLA， I PICCOLO, P CAFFARRA, M MUSICCO,* \\ T CARACENI
}

From the Istituto Neurologico "C.Besta"; and "Istituto di Tecnologie Biomediche Avanzate (CNR), Milan, Italy.

SUMMARY The frequency of dementia, the clinical characteristics and the pattern of cognitive impairment were studied in 147 unselected Parkinsonian patients. Twenty-one patients (14.28\%) were judged to be demented. They had a more severe and widespread cognitive deficit although they were affected particularly in those tests that already discriminated Parkinsonian patients from controls. A direct comparison of Parkinsonian dementia with other types of dementia is needed to validate the concept of subcortical dementia.

Since Charcot and Vulpian's observations ${ }^{1}$ about the possible mental changes in Parkinson's disease, several authors have called attention to a cognitive decline in the disease. ${ }^{23}$ However, estimates of the prevalence of dementia have ranged considerably, and studies carried out since 1960 have shown a frequency ranging from 20 to $40 \% .^{4-8}$ Inconsistencies in these findings may be accounted for by several factors such as patient selection or different methods of psychometric evaluation. Several studies have described pervasive cognitive changes, ${ }^{-11}$ whereas others have disclosed more specific deficits in visual discrimination and visuospatial orientation, ${ }^{12-14}$ verbal fluency, ${ }^{15}$ memory, ${ }^{1617}$ frontal lobe functions and conceptual abilities. ${ }^{18-20}$ Mayeux suggested that there was a continuum from slight to severe intellectual impairment in Parkinson's disease $^{2}$ and that selective neuropsychological disorders were insufficient to diagnose dementia.

One recent paper ${ }^{21}$ estimated that $15 \%$ of patients displayed cognitive dysfunction compatible with dementia.

The aim of the present study was to evaluate further the frequency of dementia, the clinical characteristics and the pattern of cognitive impairment in an unselected population of Parkinsonians referred to our Centre for Extrapyramidal Disorders for diagnosis and treatment.

\section{Patients and Methods}

The series was 147 consecutive patients $(69$ females and 78

Address for reprint requests: Professor $T$ Caraceni, Istituto Neurologico “C.Besta”, Via Celoria, 11, 20133 Milan, Italy.

Received 11 September 1987 and final revised form 4 August 1988. males) referred to the Centre for Extrapyramidal Disorders of the Istituto Neurologico "C.Besta" in a period of 16 months. Most patients were studied as out-patients. More severe cases were admitted to improve drug schedule and disease control and were evaluated as in-patients.

The diagnosis of idiopathic Parkinson's disease was established by the presence of clinical features (resting tremor, bradykinesia, rigidity and postural instability) and response to antiparkinsonian drugs. No patient had undergone surgical treatment. Patients with secondary Parkinsonism or with clinical evidence of involvement of other major neuroanatomical system (pyramidal and cerebellar signs, oculomotor abnormalities) were excluded.

The diagnosis of dementia was based on DSM-III criteria ${ }^{22}$ (see also Results) and was agreed upon by two examiners in each single case relying on interviews with patients and relatives. Particular care was taken to assess whether confusion, delusions and hallucinations were present and whether they could be modified by drug schedule variations. Lack of improvement of cognitive functions after dose reduction or drug withdrawal where appropriate, led to a diagnosis of dementia despite the clinical evidence of hallucinations, delusion and confusion. In general terms, an effort was made to examine patients when their treatment was optimised. Patients with transient confusional states were examined when free of psychotic symptoms. Patients experiencing significant motor fluctuations were examined during the on phase of the disease.

Clinical and psychometric examination was performed in 2 days. Disease severity was assessed according to the Columbia University Rating Scale (CURS) scored at the time of examination. Parkinsonian patients had a mean age of 60.97 , SD 10 years and a mean educational level of 7.06, SD 3.78 years. Disease duration was 6.62 , SD 4.49 years. Mean total CURS score was $25 \cdot 01$, SD 11.96 .

At the time of evaluation, some patients were being treated with levodopa plus peripheral decarboxylase inhibitors alone (48 patients) or in combination with dopamine-agonists (26 subjects) or with anticholinergics (28 subjects) or with both 
Table 1 Clinical and therapeutic characteristics (mean SD) of non-demented (PD) and demented (PD-D) parkinsonian patients

\begin{tabular}{|c|c|c|c|}
\hline & $P D(n=126)$ & $P D-D(n=21)$ & Significance \\
\hline $\begin{array}{l}\text { Age at latest neurol exam (yr) } \\
\text { Education (yrs) } \\
\text { Duration of illness (yrs) } \\
\text { Severity of illness (CURS total score) } \\
\text { On-off and end-of-dose deterioration phenomena } \\
\text { Abnormal involuntary movements (AIMs) } \\
\text { Psychotic side effects }\end{array}$ & $\begin{array}{l}59 \cdot 7 \text { SD } 9 \cdot 63 \\
7.38 \text { SD } 3 \cdot 9 \\
6.09 \text { SD } 4 \cdot 32 \\
23.05 \text { SD } 11 \cdot 4 \\
57 / 87^{*}(66 \%) \\
59 / 87^{*}(68 \%) \\
14 / 126(11 \%)\end{array}$ & $\begin{array}{l}66 \cdot 4 \text { SD } 2 \cdot 7 \\
6 \cdot 98 \text { SD } 2 \cdot 7 \\
9 \cdot 14 \text { SD } 4 \cdot 33 \\
34 \cdot 50 \text { SD } 10 \cdot 7 \\
16 / 21(76 \%) \\
11 / 21(52 \%) \\
19 / 21(90 \%)\end{array}$ & $\begin{array}{l}\mathrm{p}<0.01 \\
\mathrm{~ns} \\
\mathrm{p}<0.01 \\
\mathrm{p}<0.01 \\
\mathrm{~ns} \\
\mathrm{~ns} \\
\mathrm{p}<0.001\end{array}$ \\
\hline
\end{tabular}

*Number of patients (87) on levodopa therapy alone or in combination with dopamine agonists and anticholinergics (see Methods).

Table 2 Cognitive performances in controls $(C)$ (mean $S D$ )

\begin{tabular}{lr}
\hline & $C(n=51)$ \\
\hline Block Designs & 8.01 SD 2.08 \\
Object Assembly & 7.20 SD $2 \cdot 50$ \\
Zazzo's Test & 39.72 SD 12.6 \\
Benton's Test & 19.59 SD $5 \cdot 78$ \\
Similarities & 9.37 SD $2 \cdot 71$ \\
Vocabulary & 10.03 SD $3 \cdot 18$ \\
Set Test & 46.60 SD 11.06 \\
Short Tale & 7.20 SD 3.20 \\
\hline
\end{tabular}

dopamine-agonists and anticholinergics (6 subjects). Other patients were on dopamine-agonists (21 subjects) or on anticholinergics ( 9 subjects). Finally, nine patients were untreated.

As regards evaluation of on-off phenomena and dyskinesia, only patients at risk for such phenomena (that is patients being treated with levodopa alone or in combination with anticholinergics or dopamine-agonists) were considered, not including therefore patients on dopamine-agonists or anticholinergics alone (table 1).

Fifty-one normal control subjects (21 females and 30 males) matched for age (59.07, SD 7.4 years) and educational level (6.72, SD 3.29 years) with no history of central nervous system disorders were drawn from the hospital records and patients' relatives and were examined during the same period.

The neuropsychological battery, described in detail elsewhere ${ }^{23}$ included the following tests: Set Test, a test of verbal fluency; ${ }^{24}$ Short Tale Test from Randt Memory Test; ${ }^{25}$ Benton's Visual Orientation Line Test, a test of visuo-spatial orientation; ${ }^{26}$ Zazzo's Test, a test of attention which also requires visuo-motor abilities (measure of performance is the speed of execution); ${ }^{27}$ Block Designs, a subtest of the Wechsler Adult Intelligence Scale (WAIS) which requires constructional abilities; Object Assembly another subtest of WAIS which tests visual organisation; Vocabulary and Similarities subtests of the WAIS which test verbal abilities. The scores of the tests were standardised on the means and standard deviations of the 51 control subjects which are shown in table 2 .

Such transformation ( $Z$ scores) allowed a comparison between different tests and an appreciation of the different impairment of the patients in different tests.

The statistical analysis included Student's $t$ test, chi square test and a univariate analysis of variance.

Finally, the percentage of Parkinsonians and demented Parkinsonian patients scoring less than 2 or 3 standard deviations was calculated.

\section{Results}

Twenty-one Parkinsonian patients (14.28\%) were classified as demented according to DSM-III criteria (table 1). All demented Parkinsonian patients (PD-D) had had cognitive impairment for at least 6 months. They had social and occupational impairment due to mental but not to motor deficits. All PD-D had clinical and historical evidence of change in personality, impairment of abstraction and memory problems. No PD-D patients had aphasic, apraxic or agnosic disturbances at clinical examination.

Table 1 shows the main clinical and therapeutic characteristics of Parkinson's disease and PD-D patients. Among Parkinson's disease patients, nine were still untreated while the other 117 were on medication: 21 were on dopamine-agonists, nine were on anticholinergics, 39 were on levodopa plus a peripheral decarboxylase inhibitor (PDI) alone, 20 were on levodopa + PDI and dopamine-agonists, 22 were on levodopa + PDI and anticholinergics and finally six patients were on levodopa therapy + PDI and both dopamine-agonists and anticholinergics. The mean daily levodopa dosage was 646.01 , SD $273.93 \mathrm{mg}$. PD-D subjects were all on levodopa plus a peripheral decarboxylase inhibitor alone (nine subjects) or in combination with dopamine-agonists (six subjects) or with anticholinergics (six subjects). The mean daily levodopa dosage was $741 \cdot 80$, SD $300.91 \mathrm{mg}$.

PD-D patients were older and had more severe disability than Parkinson's disease patients. On-off, wearing off phenomena and abnormal involuntary movements (AIMS) did not differ between groups. Pyschotic side effects (hallucinations, delusions and

Table 3 Psychotic side effects in non-demented (PD) and demented (PD-D) Parkinsonian patients

\begin{tabular}{llc}
\hline & $P D$ & $P D-D$ \\
\hline Hallucinations & 8 & 2 \\
Delusions & 2 & 0 \\
Confusional states & 4 & 17 \\
\hline
\end{tabular}


Table 4 Frequency of dementia in various age groups

\begin{tabular}{|c|c|c|c|}
\hline Age (years) & $\begin{array}{l}\text { Non-demented } \\
\text { Parkinsonians } \\
(P D) \\
(n=126)\end{array}$ & $\begin{array}{l}\text { Demented } \\
\text { Parkinsonians } \\
(P D-D) \\
(n=21)\end{array}$ & $\begin{array}{l}\text { Percentage } \\
\text { of } \\
\text { dementia }\end{array}$ \\
\hline $\begin{aligned} &< 40 \\
& 40-49 \\
& 50-59 \\
& 60-69 \\
& \geqslant 70\end{aligned}$ & $\begin{array}{r}4 \\
13 \\
43 \\
42 \\
24\end{array}$ & $\begin{array}{l}0 \\
1 \\
4 \\
8 \\
8\end{array}$ & $\begin{array}{r}- \\
7 \cdot 1 \\
8 \cdot 5 \\
16 \cdot 0 \\
25 \cdot 0\end{array}$ \\
\hline
\end{tabular}

confusional states) were significantly more frequent in PD-D group (19 out of 21 patients) (table 1).

Table 3 shows the characteristics of psychotic side effects in Parkinson's disease and PD-D patients. In the Parkinson's disease group, psychotic side effects were similar to those found in the PD-D group even though less severe.

Table 4 shows the distribution of dementia according to age in our population. As it is evident, dementia was more prominent in older age groups. Psychometric evaluation could not be performed in five PD-D patients because of severe motor impairment and cognitive decline.

Table 5 shows the percentage of Parkinson's disease and PD-D patients scoring less than the controls' means minus 2 or 3 SD in different tests. Provided that in a normal population $2.5 \%$ of subjects are expected to score less than the normal mean minus 2 SD in a given test, it is evident from table 5 that Parkinson's disease patients were impaired only in Block Designs, Zazzo's Test and Benton's Test in a proportion greater than that expected. On the contrary, PD-D patients scored less than $2 \mathrm{SD}$ in all tests in a proportion greater than that expected. In PD-D patients, the percentage of patients scoring less than 2 SD varied widely ranging from $6.3 \%$ in Vocabulary and Short Tale to $81.3 \%$ in Block Designs and Zazzo's Test. Block Designs proved the most sensitive test in that $62.5 \%$ of patients scored less than 3 SD. Table 6 shows a comparison of $\mathrm{Z}$ scores of Parkinson's disease and
Table 6 Comparison of $Z$ scores of non-demented (PD) and demented ( $P D-D)$ parkinsonian patients in different cognitive tests (mean SD)

\begin{tabular}{lll}
\hline Tests & $P D(n=126)$ & $P D-D(n=16)$ \\
\hline Block Designs & -0.443 SD 1.431 & -3.069 SD $0.839 \ddagger$ \\
Object Assembly & -0.261 SD 1.052 & -1.830 SD $0.617 \dagger$ \\
Zazzo's Test & -0.758 SD 1.233 & -2.492 SD $0.627 \dagger$ \\
Benton's Test & -0.238 SD 1.052 & -2.372 SD $1.188 \ddagger$ \\
Similarities & 0.077 SD 1.156 & -1.797 SD $0.943 \ddagger$ \\
Vocabulary & 0.102 SD 1.005 & -1.326 SD $0.588+$ \\
Set Test & -0.184 SD 0.990 & -1.534 SD $0.879 \dagger$ \\
Short Tale & -0.278 SD 1.004 & -1.019 SD 0.608*
\end{tabular}

${ }^{*} p<0.005$; Univariate analysis of variance was performed. $t p<$ $0.0001 ; \ddagger \mathrm{p}<0.00001$.

PD-D in different tests. PD-D had significantly worse scores in all tests. They were especially impaired in Zazzo's Test and Block Designs.

\section{Discussion}

The frequency of dementia in our series was lower than that reported in other studies in which definite criteria for dementia were used. ${ }^{4-8}$ In our study the frequency was similar to the value reported by Mayeux et $a l^{8}$ in 355 patients and to that predicted by Brown and Marsden ${ }^{21}$ in a review on the methodological aspects in the diagnosis of dementia in Parkinson's disease. Such discrepancy can be explained on the one hand by a selection bias in our study concerning patients referred to a centre for movement disorders thus including patients in whom the reasons for referral were more likely motor problems rather than intellectual decline, thus underestimating the true frequency of dementia in the general population of Parkinson's disease patients. On the other hand, the discrepancy may also be accounted for by the older age of the patients in other reports. It should be mentioned that subdivision based on the various age groups in Marttila and Rinne's series, ${ }^{6}$ showed the dementia frequency in different groups to be similar to ours. The frequency of dementia increases with advancing age in Parkinson-

Table 5 Number and percentage of non-demented (PD) and demented (PD-D) parkinsonian patients scoring below 2 or 3 $S D$ of controls' means

\begin{tabular}{|c|c|c|c|c|c|c|c|c|}
\hline \multirow[b]{2}{*}{ Tests } & \multicolumn{4}{|c|}{ Below $2 S D$} & \multicolumn{4}{|c|}{ Below 3 SD } \\
\hline & & 6) & & $\begin{array}{l}16) \\
\%\end{array}$ & & 6) & & $\begin{array}{c}16) \\
\%\end{array}$ \\
\hline $\begin{array}{l}\text { Block Designs } \\
\text { Object Assembly } \\
\text { Zazzo's Test } \\
\text { Benton's Test } \\
\text { Similarities } \\
\text { Vocabulary } \\
\text { Set Test } \\
\text { Short Tale }\end{array}$ & $\begin{array}{r}11 \\
2 \\
16 \\
8 \\
3 \\
0 \\
2 \\
1\end{array}$ & $\begin{array}{l}8 \cdot 7 \\
2 \cdot 4 \\
12 \cdot 7 \\
6 \cdot 3 \\
2 \cdot 4 \\
0 \\
1 \cdot 6 \\
0.8\end{array}$ & $\begin{array}{r}3 \\
7 \\
10 \\
4 \\
3 \\
1 \\
3 \\
1\end{array}$ & $\begin{array}{r}18 \cdot 8 \\
43 \cdot 8 \\
62 \cdot 5 \\
25 \\
18 \cdot 8 \\
6 \cdot 3 \\
18 \cdot 8 \\
6 \cdot 3\end{array}$ & $\begin{array}{l}4 \\
0 \\
0 \\
2 \\
1 \\
0 \\
0 \\
0\end{array}$ & $\begin{array}{l}3 \cdot 2 \\
0 \\
0 \\
1 \cdot 6 \\
0 \cdot 8 \\
0 \\
0 \\
0\end{array}$ & $\begin{array}{r}10 \\
0 \\
3 \\
7 \\
2 \\
0 \\
0 \\
0\end{array}$ & $\begin{array}{c}62 \cdot 5 \\
0 \\
18 \cdot 8 \\
43 \cdot 8 \\
12 \cdot 5 \\
0 \\
0 \\
0\end{array}$ \\
\hline
\end{tabular}


ians as in the general population and it appears that the additional risk is relatively mild. ${ }^{21}$

More of the PD-D patients showed hyperkinesia and motor fluctuations than did demented Parkinsonians in other reports. ${ }^{72}$ A previous study of our group $^{30}$ did not show a significant difference in the prevalence of on-off phenomena and hyperkinesia in younger onset Parkinsonians than in other Parkinsonians but stressed the earlier onset of those phenomena in younger patients. A longer disease duration in our demented patients may therefore account for the higher frequency of hyperkinesia and on-off phenomena in our demented patients. In agreement with other reports, ${ }^{72}$ our PD-D patients showed greater Parkinsonian impairment as well as increased susceptibility to psychotic disturbances induced by levodopa, anticholinergics and dopamine-agonists. ${ }^{31}{ }^{32}$

It may be argued that the greater symptom severity of the PD-D group might be partly due to a lower mean levodopa dosage. That was not the case; the mean levodopa dosage for PD-D patients was $741 \cdot 80$, SD $300.91 \mathrm{mg}$, whereas mean levodopa dosage for Parkinson's disease patients was 646.01, SD \pm 273.93 $(p=n s)$. This supports the notion that greater disease severity accounted for greater symptom severity in PD-D and that suboptimal treatment was not the cause of the difference in symptom severity.

Moreover, none of the PD-D patients was on monotherapy with either dopamine-agonists or anticholinergics, whereas many of the Parkinson's disease patients were either on dopamine agonists alone (22 subjects) or on anticholinergics alone (nine subjects) or even still untreated (nine subjects).

With this respect it is well-known that only mildly impaired Parkinsonian patients may obtain the advantage of anticholinergics or dopamine agonists because these drugs are less effective than levodopa.

Interestingly, Parkinson's disease patients showed fewer confusional states and psychotic symptoms despite the fact that the percentage of Parkinson's disease patients treated with anticholinergics alone or in combination with levodopa was similar (31\%) to that of PD-D patients $(28 \%)$ treated with the association of levodopa plus anticholinergics.

An open question is whether PD-D patients have a different pattern of cognitive impairment from Parkinson's disease. Our results showed that some cognitive functions were preserved whereas others were impaired in Parkinson's disease. The percentage of Parkinson's disease scoring less than 2 SD was that expected by chance in verbal tests, memory and Object Assembly. On the contrary, Zazzo's Test and Block Designs appeared to be particularly impaired in Parkinson's disease. Such test required sustained attention and perceptual motor abilities.

The selective cognitive impairment we observed in
Parkinson's disease, is evidence against the idea of a widespread cognitive deficit in that disease." Our results indicated that tests requiring visuo-spatial analysis and motor control were especially impaired in Parkinson's disease. Such tests have been shown to be at least partially dependent on the simple and complex motor abnormalities of Parkinson's disease. ${ }^{36}$ In agreement with other reports, ${ }^{33}$ we observed also an impairment of visuo-spatial orientation. This point remains more controversial, however.

Recently, Della Sala $e t a^{\beta 4}$ and Brown and Marsden $^{35}$ reported no alterations of visuo-spatial abilities in Parkinson's disease. However, they based their conclusions on the study of a selected sample of Parkinsonians. In that regard, it is appropriate here to consider some methodological aspects of our present study to appreciate better the significance of our results based on the analysis of a large sample of patients. Only a small percentage of our Parkinson's disease patients had performances inferior to $2 \mathrm{SD}$ of controls even in the most affected tests. Brown and Marsden, reviewing the subject matter of cognitive impairment in Parkinson's disease, ${ }^{37}$ concluded that their performance was within normal limits showing only a slight impairment when compared with controls. Accordingly, the consistent variability ${ }^{20}$ in cognitive performances of Parkinson's disease in different studies is probably due to a selection bias in some studies including in some series patients with global cognitive impairment who may well have been regarded as demented.

In our series, some patients appeared to be more compromised in some specific tests, as became clear when patients were classified according to the mean and SD of the controls, suggesting that those tests may have revealed general cognitive deterioration better than others. Therefore, the existence of specific cognitive deficits along with the presence in our series of patients with borderline dementia, may have accounted for the worse performance of the whole group of Parkinson's disease patients in the tests more sensitive to mental decay.

Our present study, which was descriptive in nature, did not allow the definition of subgroup $s^{38}$ with specific alterations for instance in memory, cognitive planning or visuo-spatial deficits. However, our results in PD-D may shed some light on the characteristics of cognitive impairment in Parkinson's disease. Our PD-D showed a global cognitive decline involving all cognitive aspects. Nevertheless, the outline of their cognitive impairment followed that of Parkinson's disease. In fact, PD-D were impaired above all in perceptive visual tests and attention tests which already best discriminated Parkinson's disease from controls. This suggests that those cognitive functions already impaired in Parkinson's disease are impaired above all 
because of the dementing process. The specificity of such observations, however, needs to be demonstrated by a comparison with other dementing diseases, especially Alzheimer disease. Recently, Huber $e t a \beta^{9}$ found evidence for different patterns of cognitive involvement in demented Parkinsonian patients versus Alzheimer's patients, thus suggesting that subcortical dementia ${ }^{40}$ is a useful concept to describe cognitive impairment in Parkinsonians. These results need confirmation since it appears that subcortical dementia is a useful concept in clinical terms but it still lacks clear-cut neuropsychological evidence.

This work was funded, in part, by grants from the Ministero della Sanità d'Italia and from the Knoll S.p.A Prodotti Farmaceutici-Italia.

\section{References}

1 Charcot JM, Vulpian A. De la paralysie agitante. Gaz Hebdom Méd Chir 1861;8:756-67.

2 Mayeux R. Depression and dementia in Parkinson's disease. In: Marsden CD, Fahn S, eds. Movement Disorders. London: Butterworth 1982:75-95.

3 Mortimer JA, Christensen KJ, Webster DD. Parkinsenian dementia. In: Frederiks JAM, eds. Handbook of Clinical Neurology Vol. 46. Amsterdam: Elsevier 1985:371-84.

4 Pollack M, Hornabrook RW. The prevalence, natural history and dementia of Parkinson's disease. Brain 1966;89:429-48.

5 Celesia GG, Wanamaker WH. Psychiatric disturbances in Parkinson's disease. Dis Nerv Syst 1972;33:577-83.

6 Marttila RJ, Rinne UK. Dementia in Parkinson's disease. Acta Neurol Scand 1976;54:431-41.

7 Lierberman A, Dziatolowski M, Kupersmith M, et al. Dementia in Parkinson's disease. Ann Neurol 1979;6:355-59.

8 Rajput AH, Offord K, Beard CM, Kurland LT. Epidemiological survey of dementia in parkinsonism and control population. In: Hassler RG, Christ JF, eds. Parkinson-specific Motor and Mental Disorders. Role of the Pallidum: Pathophysiological, Biochemical and Therapeutic Aspects. Advances in Neurology Vol. 40. New York: Raven Press, 1984:229-34.

9 Reitan RM, Boll TJ. Intellectual and cognitive functions in Parkinson's disease. J Consult Clin Psychol 1971;37:364-9.

10 Portin R, Raininko R, Rinne UK. Neuropsychological disturbance and central atrophy determined by computerized tomography in parkinsonian patients with long-term levodopa treatment. In: Hassler RG, Christ JF, eds. Parkinson-specific Motor and Mental Disorders. Role of the Pallidum: Pathophysiological, Biochemical and Therapeutic Aspects. Advances in Neurology Vol. 40. New York: Raven Press, 1984:219-29.

11 Pirozzolo FJ, Hansch EC, Mortimer JA, Webster DD, Kuskowski MA. Dementia in Parkinson's disease: a neuropsychological analysis. Brain Cog 1982;1:71-83.

12 Proctor F, Riklan M, Cooper IS, Teuber HL. Judgement of visual and postural vertical by parkinsonian patients. Neurology 1964;14:287-93.

13 Bowen FP, Hoehn MM, Yahr MD. Parkinsonism: alterations in spatial orientation as determined by a route walking test. Neuropsychologia 1972;10:355-61.

14 Mortimer JA, Pirozzolo FJ, Hansch EC, Webster EC, Webster DD. Relationship of motor symptoms to intellectual deficits in Parkinson disease. Neurology 1982;32:133-7.

15 Matison R, Mayeux R, Rosen J, Fahn S. Tip of the tongue phenomenon in Parkinson's disease. Neurology 1982;32:567-70.

16 Bowen FP, Burns MM, Yahr MD. Alterations in memory processes subsequent to short and long-term treatment with $L$ dopa. In: Birkmayer W, Hornykiewicz $\mathrm{O}$, eds. Advances in
Parkinsonism. Vth International Symposium on Parkinson's disease. Basel: Hoffman-La Roche 1976:488-91.

17 Halgin R, Riklan M, Misiak H. Levodopa, parkinsonism and recent memory. J Nerv Ment Dis 1977;164:268-72.

18 Lees AR, Smith E. Cognitive deficits in the early stages of Parkinson's disease. Brain 1983;106:257-70.

19 Cools AR, Van Den Bercken JHL, Horstink MWI, Van Spaendonck KPM, Berger HJC. Cognitive and motor shifting aptitude disorder in Parkinson's disease. J Neurol Neurosurg Psychiatry 1984;47:443-52.

20 Taylor AE, Saint-Cyr JA, Lang AE. Frontal lobe dysfunction in Parkinson's disease. Brain 1986;109:845-83.

21 Brown RG, Marsden CD. How common is dementia in Parkinson's disease? Lancet 1984;ii:1262-5.

22 Diagnostic and Statistical Manual of Mental Disorders. Third Edition. Washington, DC, American Psychiatric Association 1980.

23 Girotti F, Carella F, Grassi MP, Soliveri P, Marano R, Caraceni T. Motor and cognitive performances of Parkinsonian patients in the on and off phases of the disease. $J$ Neurol Neurosurg Psychiatry 1986;49:657-60.

24 Isaac B, Kennie AT. The set test as an aid to the detection of dementia in old people. Br J Psychiatry 1973;123:467-70.

25 Randt CT, Brown ER, Osborne DP Jr. A memory test for longitudinal measurement of mild to moderate deficits. Clin Neuropsychol 1980;2:184-94.

26 Benton AL, Varney NR, Hamsher $\mathrm{K}$ de $\mathrm{S}$. Visuospatial judgement. A clinical test. Arch Neurol 1978;35:364-7.

27 Zazzo R. Manuel Pour l'examen Psychologique de l'enfant. Neuchatel: Delachaux et Niestlé 1969.

28 Mayeux R, Rosenstein R, Stern J, Cote L, Fahn S. The prevalence and risk of dementia in idiopathic Parkinson's. Ann Neurol 1986;20:128.

29 Elizan TS, Sroka H, Maker H, Smith H, Yahr MD. Dementia in idiopathic Parkinson's disease. Variables associated with occurrence in 203 patients. $J$ Neurol Transm 1986;65:285-302.

30 Caraceni T, Giovannini P, Girotti F, Grassi MP, Piccolo I, Soliveri P. Juvenile parkinsonism: a different clinical expression of Parkinson's disease. J Neurol 1985;232(Suppl):66.

31 De Smet Y, Ruberg M, Serdaru M, Dubois B, Lhermitte F, Agid $Y$. Confusion, dementia and anticholinergics in Parkinson's disease. J Neurol Neurosurg Psychiatry 1982;45:1161-4.

32 Agid Y, Ruberg M, Dubois B, Javoy-Agid F. Biochemical substrates of mental disturbances in Parkinson's disease. In: Hassler RG, Christ JF, eds. Parkinson-specific Motor and Mental Disorders. Role of the Pallidum: Pathophysiological, Biochemical and Therapeutic Aspects. Advances in Neurology Vol. 40. New York: Raven Press, 1984:229-34.

33 Boller F, Passafiume D, Keefe NC, Rogers K, Kim Y. Visuospatial impairment in Parkinson's disease. Arch Neurol 1984;41:485-90.

34 Della Sala S, Di Lorenzo G, Giordano A, Spinnler H. Is there a specific visuo-spatial impairment in Parkinsonians? J Neurol Neurosurg Psychiatry 1986;49:1258-65.

35 Brown RG, Marsden CD. Visuospatial function in Parkinson's disease. Brain 1986;109:987-1002.

36 Girotti F, Soliveri P, Carella F, Geminiani G, Aiello G, Caracen T. Role of motor performances in cognitive processes of parkinsonian patients. Neurology 1988;38:537-40.

37 Brown RG, Marsden CD. Neuropsychology and cognitive function in Parkinson's disease: an overview. In: Marsden CD Fahn S, eds. Movement Disorders 2. London: Butterworth, 1987: 99-123.

38 El-Awar M, Becker JT, Hammond KM, Nebes RD, Boller F. Learning deficit in Parkinson's disease: comparison with Alzheimer's disease and normal aging. Arch Neurol 1987;44: $180-4$.

39 Huber SJ, Shuttleworth EC, Paulson GW, Bellchambers MJG, Clapp LE. Cortical vs subcortical dementia. Neuropsychological differences. Arch Neurol 1986;43:987-90.

40 Freedman M, Albert M. Subcortical dementia. In: Frederiks JAM, ed. Handbook of Clinical Neurology. Vol. 46. Amsterdam: Elsevier 1985:311-6. 